\title{
Resistencia a la violencia política y defensa de la territorialidad comunitaria en el departamento del Cauca, Colombia (1971-2012) ${ }^{1}$
}

\author{
Resistance to political violence and defense of \\ community territoriality in the Department of Cauca, \\ Colombia (1971-2012)
}

\begin{abstract}
Resistência à violência política e recriação da territorialidade comunitária no Conselho Regional Indígena do Cauca, Colômbia (1971-2012)
\end{abstract}

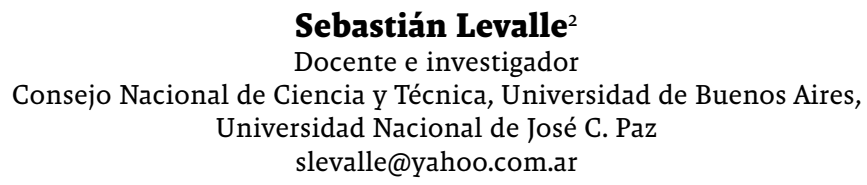

Recibido: $21-11-16$ Aprobado: 02-11-17

1 Este artículo es una versión ampliada y revisada de la ponencia "Resistencia a la violencia política y defensa de la territorialidad comunitaria en el suroccidente colombiano (1971-2012)" presentada en las XV Jornadas Interescuelas/ Departamentos de Historia, 17/9/2015, Comodoro Rivadavia, Chubut. Las actividades necesarias para la realización de este trabajo han sido parcialmente subsidiadas por el Proyecto de Investigación Plurianual "Condiciones sociohistóricas de la violencia rural en América Latina, 1950s-1990s" (CONICET).

2 Magíster en Estudios Sociales Latinoamericanos. 


\section{Resumen}

En este artículo se explican las transformaciones de la resistencia indígena a la violencia política. Resistencia liderada por el Consejo Regional Indígena del Cauca -CRIC- desde su fundación en 1971 hasta el comienzo de los últimos diálogos de paz en el 2012. Para ello se ensayó un abordaje socio-histórico de media duración, que se nutre del análisis de un conjunto de indicadores estadísticos. En el artículo se plantea que la lucha de las comunidades indígenas del CRIC expresa un conflicto entre distintas territorialidades en pugna que encarnaban diversos proyectos de orden social. También, se afirma que las transformaciones de la resistencia indígena se explican por la confluencia de tres variables socio-históricas: las políticas estatales sobre distribución y uso de la tierra, el desarrollo histórico del conflicto armado, y las formas de imaginar la nación y las políticas estatales de gestión de la diversidad que a ellas se asocian.

Palabras clave: violencia; resistencia a la opresión; conflicto armado; conflicto étnico; Colombia.

\section{Abstract}

This paper explains the transformations of indigenous resistance to political violence. This resistance was led by the Consejo Regional Indígena del Cauca -CRIC- (Indigenous Regional Council of Cauca) since its foundation in 1971 until the beginning of the last peace talks in 2012. To this end, a socio-historical approach of medium duration was tried, which is based on the analysis of a set of statistical indicators. The article states that the struggle of the indigenous communities of the CRIC expresses a conflict among different territorialities in conflict embodying diverse projects of social order. Also, it is affirmed that the transformations of indigenous resistance are explained by the confluence of three socio-historical variables: the state policies on distribution and use of land, the historical development of the armed conflict, and the ways of imagining the nation and the state policies of diversity management that are associated with them.

Keywords: violence; resistance to oppression; armed conflict; ethnic conflict; Colombia.

\section{Resumo}

Neste artigo, propomos explicar as transformações da resistência indígena à violência política, através do Conselho Regional Indígena do Cauca (CRIC) desde a sua fundação em 1971 até o início dos últimos diálogos de paz em 2012. Para isso, vamos ensaiar uma abordagem sociohistórica de meia duração, que se baseia na análise de um conjunto de indicadores estatísticos. Indicamos que a luta das comunidades indígenas do CRIC expressa um conflito entre as diferentes territorialidades em conflito que incorporam diversos projetos de ordem social. O trabalho afirma que as transformações da resistência indígena são explicadas pela confluência de três variáveis sociohistóricas: as políticas estatais de distribuição e uso da terra, o desenvolvimento histórico do conflito armado e as formas de imaginar a nação e as políticas públicas de gestão da diversidade.

Palavras-chave: violência; resistência à opressão; conflito armado; conflito étnico; colômbia. 


\section{Introducción}

El departamento del Cauca, Colombia, y sus pobladores campesinos e indígenas han ganado un espacio cada vez mayor en la primera plana de los periódicos nacionales. La conformación de un corredor estratégico del conflicto armado en el norte del Cauca, atravesado por la disputa territorial entre los ejércitos paramilitares, las Fuerzas Armadas Revolucionarias de Colombia (FARC) y las Fuerzas Armadas estatales, y la resistencia incesante de las poblaciones locales, han obligado a mirar con atención a un departamento que figura entre los más rezagados de Colombia. Las comunidades indígenas caucanas han resistido a la violencia política de diversos modos, algunas veces junto a las guerrillas, otras por medio de su propia organización armada, y desde 1991 bajo un formato de resistencia civil. En este artículo nos proponemos explicar las transformaciones de la resistencia indígena a la violencia política por parte del Consejo Regional Indígena del Cauca (CRIC) desde su fundación en 1971 hasta el comienzo de los últimos diálogos de paz en el 2012.

En el enfoque adoptado para este trabajo, las condiciones socio-históricas son consideradas como una variable explicativa fundamental que permite captar la dialéctica entre estructura y agencia bajo temporalidades múltiples. En este artículo se sostiene la hipótesis de que las transformaciones en las prácticas de resistencia indígena a la violencia política en el CRIC se explican por la confluencia de tres variables socio-históricas: a) las políticas estatales sobre distribución y uso de la tierra, b) el desarrollo histórico del conflicto armado, y c) las formas de imaginar la nación y las políticas estatales de gestión de la diversidad que a ella se asocian.

Creemos que una perspectiva socio-histórica y un recorte temporal más amplio como los que aquí se proponen pueden aportar nuevos elementos para analizar la resistencia indígena a la violencia política en el Cauca. Desde principios de la década del 2000 existen trabajos que analizan los procesos de resistencia indígena al conflicto armado en el suroccidente colombiano. Los enfoques de estas investigaciones son diversos: existen trabajos que destacan los aportes de la resistencia civil para la construcción de un proceso nacional de paz (González, 2006; Hernández, 2004; 2006), otros que se concentran en la relación entre la memoria histórica y la resistencia indígena (Moreno, 2008; Peñaranda, 2012), un tercer grupo que recupera las teorías de la acción colectiva y se detiene en la descripción de los nuevos repertorios de la resistencia civil (Hernández, 2002; 2003; Sandoval, 2008; Rudqvist y Anrup, 2013), y finalmente una línea de trabajo que interpreta la resistencia indígena desde el enfoque de la violencia étnica y plantea la hipótesis de la continuidad del genocidio sobre los pueblos originarios colombianos (Espinosa, 2007; Villa y Houghton, 2005). Más cerca de nuestra perspectiva se encuentran las investigaciones que han abordado la guerrilla conformada por los indígenas del Cauca y han analizado su proceso de reinserción como movimiento político (Peñaranda, Guerrero y Zuluaga, 1999; Peñaranda, 2015). No obstante, estos trabajos no han considerado el peso explicativo de las tres variables socio-históricas que aquí seleccionamos ni se han propuesto un marco temporal de mediano alcance como el que pretendemos abordar a continuación.

Siguiendo a Ansaldi y Alberto (2014) sostenemos que la violencia política, lejos de estar asociada al desorden, se orienta a transformar las sociedades en relación con los problemas de construcción del orden social. Desde una perspectiva gramsciana, planteamos que el orden social es una construcción socio-histórica que resulta del conflicto, es la expresión concreta del poder entendido como relación de fuerzas sociales. El orden regula las relaciones de explotación por medio de las cuales un estamento o una clase social logra apropiarse del producto ajeno, un proceso que supone el uso de la violencia física.

La clase de violencia a la que nos referimos como violencia política se orienta a producir o inhibir cambios en la estructura del poder y puede ser realizada por el Estado, por organizaciones paralegales o por organizaciones insurgentes. Para llevar a cabo el análisis de la resistencia indígena a la violencia política distinguimos tres dimensiones. En primer lugar, una dimensión estructural, que es aquella en la que las mediaciones institucionales o estructurales impiden el acceso a los recursos y 
oportunidades de vida (Galtung, 1998) y se materializa en las zonas rurales primariamente en la concentración de la tierra. En segundo lugar, la violencia política armada es la acción desarrollada por un grupo organizado militarmente para cuestionar el poder del Estado o, de forma inversa, para combatir a los grupos insurgentes. Finalmente, identificamos una dimensión simbólica de la violencia, que impone y legitima los significados y los valores hegemónicos y subalterniza los conocimientos no hegemónicos.

La violencia política a la que se enfrentan las comunidades indígenas caucanas constituye un elemento socio-histórico de largo alcance que se expresa desde la Colonia en la lucha por el control del territorio y la fuerza de trabajo. En este espacio geopolítico, distintos proyectos de orden social luchan por imponerse. El Estado nacional y sus fuerzas armadas, los actores armados parainstitucionales vinculados a los sectores terratenientes, las guerrillas y las comunidades indígenas defienden distintas formas de territorialidad y proyectos alternativos de orden social que han apelado a la violencia política. En nuestro período de análisis la violencia política tiene múltiples expresiones: a las históricas formas de violencia -la estatal y la que es producto de la lucha campesina por la tierra-, se suman las violencias guerrillera, narcotraficante y parainstitucional.

La violencia política armada se ha desplegado con particular intensidad en este departamento. La presencia guerrillera en la región es tan antigua como las propias Fuerzas Armadas Revolucionarias de Colombia (FARC) e involucra prácticamente la totalidad de los grupos insurgentes, tanto los llamados "históricos" como los de "segunda generación". Esta presencia obedece a razones geopolíticas -relacionadas con la inaccesibilidad y los lazos comunicantes con otros departamentos- y estratégicas -en función del aprovechamiento del conflicto social entre las haciendas y los sectores campesinos e indígenas- (Peñaranda, 2012). A la presencia de los frentes sexto y octavo de las FARC se le sumará el Ejército de Liberación Nacional (ELN) y el Ejército Popular de Liberación (EPL). El Movimiento 19 de Abril (M19) incursionará en el Cauca desde los años de 1970 y con un menor grado de incidencia actuarán el Comando Ricardo Franco disidente de las FARC-, el Movimiento Jorge Eliécer Gaitán, el Grupo Democracia -disidente del Mı- y el Partido Revolucionario de los Trabajadores.

Con el objetivo declarado de combatir el avance guerrillero desde fines de los años de 1990 llegan las Autodefensas Unidas de Colombia, con sus bloques Farallones, Calima y Libertad. En la actualidad esta forma parainstitucional ${ }^{3}$ de violencia se expresa en el accionar delictivo de las Bandas Criminales (BACRIM), resabio de las AUC, fundamentalmente las que se identifican como Águilas Negras. Estos grupos, generalmente vinculados al narcotráfico, amenazan a las autoridades indígenas y cometen asesinatos selectivos.

Para enfrentar las múltiples formas de violencia política, los pueblos campesino-indígenas del Cauca han desplegado un proceso de resistencia que constituye al mismo tiempo un modo de recreación de la territorialidad comunitaria, es decir, de las formas en las que las comunidades indígenas del suroccidente habitan social, cultural, económica y políticamente el espacio compartido. Dicho proceso se ha plasmado fundamentalmente en cuatro planos: la recuperación de los cabildos y la ampliación de los resguardos indígenas (Castillo, 2006), la restauración de la memoria colectiva (Rappaport, 1990), la construcción de un sistema educativo comunitario (PEBI, 2004) y el planeamiento colectivo del desarrollo (Hernández, 2004). Gracias a esta política de resistencia, la organización ha lo-

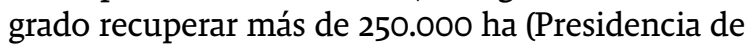
la República, 2008) que habían sido usurpadas por los hacendados y que hoy son administradas por las autoridades indígenas bajo el sistema de propiedad colectiva y usufructo familiar. En este sentido, la resistencia de los indígenas del CRIC expresa un proyecto de orden social alternativo al hegemónico, una propuesta política que recupera elementos de las cosmovisiones y de las estructuras sociales

3 Recuperando a Medina Gallego y Téllez (apud. Rodríguez, 2012) concebimos la violencia parainstitucional como una "modalidad no ortodoxa de control social" que forma parte de la construcción de la estatalidad colombiana desde el siglo XIX. 
indígenas pero que, al mismo tiempo, las reimagina utópicamente.

La recreación de la territorialidad comunitaria se ha desarrollado desde 1971 bajo diversas estrategias, alternando entre una vía armada -primero en alianza con las Fuerzas Armadas Revolucionarias de Colombia (FARC) y el Movimiento 19 de Abril (M19) y luego conformando su propia guerrilla- y una vía civil autónoma. En los dos apartados que siguen analizaremos las transformaciones en las prácticas de resistencia a la violencia política por parte de las comunidades indígenas caucanas. Antes de continuar es necesario hacer una salvedad: la periodización que construimos para abordar el recorte temporal 1971-2012 da cuenta de las formas principales -mas no exclusivas- en las que la resistencia se expresa en cada momento histórico.

\section{La resistencia armada en la nación mestiza: de las alianzas con las guerrillas al Movimiento Armado Quintín Lame (1971-1991)}

El 24 de febrero de 1971 dos mil indígenas reunidos en el municipio de Toribío fundan el Consejo Regional Indígena del Cauca. La movilización de las comunidades indígenas encontró nuevas oportunidades políticas en la coyuntura abierta por la activación de la reforma agraria bajo el gobierno del liberal Carlos Lleras Restrepo. En el marco de la Ley 135 el gobierno impulsó la organización de los sectores rurales como un medio de presión para que los latifundistas adoptaran la orientación reformista. Emergente indirecto de ese proceso, el CRIC ${ }^{4}$ expresó la situación de asedio a la que estaban sometidas las comunidades frente al avance del sistema de haciendas y los cultivos agroindustriales,

El CRIC constituye una organización multiétnica en la cual predominan los indígenas nasa y guambianos. En el departamento del Cauca conviven diez grupos indígenas distribuidos en 83 resguardos. Los indígenas representan $3,4 \%$ de la población nacional y $21,55 \%$ de la población departamental. En el Cauca habitan además comunidades afrodescendientes que representan $22,20 \%$ de la población del departamento (censo nacional 2005). principalmente la caña de azúcar (Sánchez, Vargas y Vázquez, 2011, p. 85). Para la década de 1970 $1,8 \%$ de los propietarios del Cauca concentraba $50 \%$ de las tierras productivas, y la mayor parte de los indígenas trabajaba bajo formas semiserviles en las haciendas (Peñaranda, 2015).

El avance organizativo del campesinado indígena será contestado con múltiples formas de violencia política. Las elites rurales instauraron una contrarreforma agraria sellada el 9 de enero de 1972 con el Pacto de Chicoral. Este pacto, firmado por los partidos tradicionales y los gremios de propietarios en el gobierno del conservador Misael Pastrana Borrero, termina con la política agraria redistributiva mediante un conjunto de leyes que dilatan los tiempos para la adjudicación de tierras y favorecen a los grandes propietarios (Fajardo, 2015). La orientación conservadora de la política estatal sobre la tierra no será modificada sustancialmente en todo el período 1971-2012, dando por resultado una tendencia histórica a la concentración de la propiedad rural y una desigualdad estructural en el campo (IGAC, 2012). De este modo se configura lo que aquí concebiremos como una dimensión estructural de la violencia política sobre las comunidades campesino-indígenas.

El bloqueo de la vía legal para la reforma agraria constituye un elemento fundamental para comprender el modo en el que se van a desplegar las luchas campesino-indígenas en el Cauca. La figura de la "invasión" de tierras, carente de sustento legal, aparecerá como la marca característica de la resistencia. El campesinado indígena del Cauca concebirá las invasiones de tierras como un proceso largo de recuperación de los territorios ilegítimamente usurpados por los hacendados desde los tiempos de la Colonia. Las "recuperaciones" de tierra serán el formato privilegiado de la lucha indígena desde la década de 1970.

A la dimensión estructural de la violencia política manifestada en la concentración de la tierra, se le sumó la profundización de las políticas represivas bajo los postulados de la 
Doctrina de la Seguridad Nacional'5. A su vez, la violencia contrainsurgente estatal será complementada con la violencia parainstitucional bajo la forma de grupos de pájaros al servicio de los terratenientes que procederán asesinando a varios dirigentes del $\mathrm{CRIC}^{6}$. El objetivo primario de estas formas de violencia política consistía en desarticular el proceso de recuperaciones de tierras que estaba llevando a cabo el movimiento indígena.

Para hacer frente a la violencia terrateniente y parainstitucional en el período 1971-1983 las comunidades organizadas en el CRIC establecerán alianzas con las guerrillas que operaban en su territorio. Las comunidades acudieron al EPL y al M19 para conseguir armamento y entrenamiento militar, ofreciéndoles a cambio refugio en la región de Tierradentro. Se formarán entonces los primeros núcleos de autodefensa indígena, grupos armados que actuaban intermitentemente en respuesta a la aplicación de la violencia estatal y parainstitucional.

El desarrollo de la política de alianzas ocurre en un momento histórico en el que las guerrillas actúan bajo lo que González, Bolívar y Vázquez (2002) en su análisis de las FARC denominan "lógica partisana". En este momento la guerrilla muestra un carácter defensivo, con un lento desarrollo del número de efectivos y una subordinación del accionar militar al mando político. El Cauca aparece en este momento como un escenario de refugio y de entrenamiento militar. Bajo esta dinámica del conflicto armado, las organizaciones insurgentes buscarán consolidar

5 La Doctrina de Seguridad Nacional postulaba que el enemigo al que debían atacar las Fuerzas Armadas, el comunismo internacional, se encontraba ahora en el interior de cada espacio nacional. En Colombia esta doctrina desembarcó con el plan LASO de 1964 y se institucionalizó bajo el Estatuto de Seguridad Interior promulgado por el gobierno del liberal Julio César Turbay Ayala en 1978.

6 Un informe de la División de Asuntos Indígenas del Ministerio de Gobierno da cuenta de 155 hechos de violencia contra indígenas en el Cauca entre 1972 y 1979, en su mayor parte atribuidos a terratenientes o agentes estatales. Ver: "Relación de Atropellos Cometidos a los Indígenas del Cauca a partir del año 1972", citado en Peñaranda (2015). su presencia territorial a partir del apoyo de las poblaciones locales.

Por otra parte, en los años de 1970 la conciencia nacional imaginaba la nación colombiana como la patria del mestizo, asimilando al indígena al pasado y al atraso cultural. Aún sobrevivía la Constitución de 1886 que portaba una idea de nación blanca, católica e hispanohablante. La gestión estatal de la diversidad se sustentaba en la Ley 89 de 1890 que contenía un fuerte carácter racista y una voluntad explícita de blanqueamiento cultural (Pineda, 1997; Laurent, 2010). Sobre este imaginario los indígenas aparecen como campesinos empobrecidos, sector social que constituía la base social fundamental de los movimientos guerrilleros. Las organizaciones armadas consideraban que existían objetivos comunes. Desde los años de 1930 el Partido Comunista Colombiano proclamaba la liberación de las "nacionalidades oprimidas" (Pumarada, 2013). Lo mismo ocurre desde varios sectores del movimiento indígena que se asumen como integrantes del "pueblo explotado" (Castillo, 2006). Por otra parte, guerrillas y comunidades indígenas consideran el Estado colombiano como un Estado ilegítimo. Para las primeras, la falta de legitimidad del Estado deriva de su carácter clasista mientras que para las segundas ella es un producto de su carácter monocultural. En ambos casos, el Estado aparece como una imposición injusta.

La lógica partisana de las guerrillas y el imaginario nacional basado en el mestizaje favorecerán las alianzas entre las comunidades y las organizaciones insurgentes. No obstante, los objetivos divergentes tensarán las relaciones entre las comunidades y los actores armados. La idea de la autodefensa, presente en la historia larga del movimiento indígena caucano, se funda en la protección de los resguardos frente a la violencia terrateniente. La relación de las comunidades con el Estado desde tiempos coloniales esta permeada por la búsqueda del reconocimiento jurídico de sus territorios y de su autonomía político-administrativa (Lemaitre, 2013; Platt, 1999). Esta tradición de demanda frente al Estado entra en contradicción con la 
voluntad de toma del poder de las organizaciones insurgentes.

Desde 1975 los grupos de autodefensa indígena se distancian del EPL cuando este enfoca su acción en el combate contra el Estado. La divergencia original en los propósitos organizativos de las autodefensas indígenas y de las guerrillas se profundizará hacia fines de la década de 1970. A partir de 1977 las FARC se transforman en una guerrilla ofensiva con más autonomía militar respecto del mando político del Partido Comunista (González et al., 2002). En el Cauca, la nueva orientación de la organización armada se traduce en una vocación por el control absoluto del territorio, lo cual genera tensiones con las autoridades indígenas. Además, las recuperaciones de tierras entraban en contradicción con el sistema extorsivo que las FARC les imponían a los hacendados a cambio de la protección de sus tierras.

Por otra parte, la acción contrainsurgente se institucionalizó durante la presidencia de Julio César Turbay Ayala con la promulgación del Estatuto de Seguridad Interior (Decreto 1923/78). Tras el amparo de esta norma se llevaron a cabo sistemáticas violaciones de derechos humanos y se facultó a la justicia penal militar para juzgar a los acusados por delitos vinculados al conflicto armado. Bajo este estatuto se produjo una fuerte ofensiva contra el Mi9 en el marco de la cual el presidente del CRIC, varios asesores y más de un centenar de líderes comunitarios fueron detenidos y torturados por el ejército (Sánchez et al., 2011).

El incremento sostenido de la violencia política a manos de los terratenientes, los pájaros y las Fuerzas Armadas, el freno del proceso de recuperaciones de tierras y las tensiones crecientes entre las guerrillas y las comunidades indígenas del Cauca explican la transformación de los grupos de autodefensa indígena en una organización militar permanente (Hernández, 2006; Peñaranda, 2012; 2015; Rappaport, 2004). En 1984 algunos sectores del movimiento indígena consideraron necesario organizar su propia guerrilla para defender sus territorios y su modo de vida dando origen al Movimiento Armado Quintín Lame (MAQL).
El MAQL fue un grupo fuertemente territorializado que contó con las comunidades indígenas del norte del departamento del Cauca como su base de apoyo. Creó cuatro frentes y sus objetivos militares fueron algunos terratenientes y los grupos de pájaros. Su composición de base fue mayoritariamente indígena pero participaron también combatientes afrodescendientes y blancos que totalizaron entre 150 y 200 integrantes (Ibeas, 1995). Si bien el Quintín Lame operó una transformación al pasar de autodefensa indígena a un formato de guerrilla permanente, su accionar "se orientó menos hacia los objetivos tradicionales de los grupos guerrilleros y más, a apuntalar a las autoridades tradicionales de las comunidades, que aceptaron su presencia solo en la medida en que este objetivo se cumplió" (Peñaranda, 2012, p. 178).

La recreación armada de la territorialidad comunitaria marcará un nuevo momento en la resistencia a la violencia política en el Cauca. Según Sánchez et al. (2011) el MAQL logró que los grupos guerrilleros respetaran la autonomía indígena y al mismo tiempo evitó la inserción de grupos paramilitares en la región. Sin embargo, las organizaciones comunitarias van a entrar en tensión con el Quintín Lame a medida que este se inserte cada vez más en las dinámicas típicas del conflicto armado, adoptando él también una orientación ofensiva y alejándose de su territorio. Por una parte, la disputa por el control territorial enfrentó al MAQL con otros grupos guerrilleros -fundamentalmente las FARC y el Ejército de Liberación Nacional (ELN)-, y por la otra, la incorporación del MAQL a la Coordinadora Guerrillera Simón Bolívar (CGSB) en 1987 implicó una progresiva pérdida de control comunitario sobre el accionar del movimiento (Ibeas, 1995).

A medida que el MAQL fue adoptando las lógicas tradicionales de los grupos armados, las comunidades indígenas comenzaron a hacer explícito su distanciamiento. Las organizaciones indígenas se venían pronunciando contra la presencia de los actores armados en sus territorios desde 1984. El CRIC denunció por primera vez al Sexto Frente de las FARC por el asesinato de Ramón Julicue, dirigente del resguardo de San Francisco, en un atentado dirigido al gobernador del cabildo. Al mismo tiempo el Movimiento de Autoridades Indígenas de Colombia 
(AICO) - un desprendimiento del CRIC- promovió la primera movilización contra los actores armados y puso el foco en el control comunitario del MAQL: "Esto es lo que pasa con el grupo Quintín Lame, que se ha dedicado a servir de policía, a perseguir unos cuatreros (porque otros están en sus filas) y a remplazar la autoridad de los cabildos, aunque diga que los respeta" (Declaración de AICO apud. Peñaranda, 2012, p. 192). Un mes después el CRIC publicó un documento titulado "Acta de Andalucía" donde exhortó a las guerrillas a abandonar los territorios indígenas. La posición de autonomía frente a los actores externos se afirmó con la "Resolución de Vitoncó" elaborada por representantes de 45 cabildos en febrero de 1985 .

El Quintín Lame, presionado por las comunidades y subordinado en la CGSB a la hegemonía de las organizaciones armadas más poderosas -FARC y ELN- se desmoviliza en 1991, un año después que el Mi9, y se integra al juego político bajo el nombre de Alianza Social Indígena.

\section{La resistencia civil en la nación multicultural: una vieja lucha bajo nuevos repertorios (1991- 2012)}

Entrada la década de 1990 la dimensión estructural de la violencia política sobre las comunidades indígenas se intensifica. La tendencia histórica a la concentración de la tierra se profundiza desde la aprobación de la Ley 160 que establece la política del mercado asistido de tierras, terminando con la intervención directa del Estado en el campo 7 . Si bien en el Cauca ha existido en los últimos años un

7 Este enfoque promovido por el Banco Mundial continuará en las legislaciones posteriores, como en la Ley 1448 de reparación a las víctimas del conflicto armado interno del 2011. Esta ley promueve la restitución material y jurídica de tierras a las víctimas o en su defecto la compra de nuevas tierras, pero evita las expropiaciones y renuncia a las compras estatales. De este modo la Ley 1448 no afecta la estructura agraria ni los poderes existentes en el campo, limitando su accionar a las tierras "inertes y mal administradas" (CNMH, 2013, pp. 129-130). Su mayor importancia radica quizás en que por primera vez con claridad el Estado afirma la existencia de un conflicto armado interno que conlleva un proceso masivo de desplazamiento, despojo y abandono de tierras. aumento del número de propietarios, los predios adquiridos han sido pequeños y de mala calidad, por lo que la estructura de la propiedad agraria no se modificó sustancialmente (IGAC, 2012). Tal situación se refleja en el crecimiento sostenido del coeficiente de Gini (figura l) y contribuye a explicar la persistencia de la resistencia indígena.

Hacia el final de los años de 1990 el conflicto armado recrudece y se redefine su lógica de funcionamiento. Los actores responsables de la violencia parainstitucional sufren transformaciones importantes: los grupos de pájaros dejan de operar como autodefensas en función de los intereses terratenientes para conformar un ejército paramilitar de carácter ofensivo al servicio de la expansión de los latifundios narcotraficantes -principalmente el Cartel de Cali- y la economía agroindustrial (Sánchez et al., 2011; Ibeas, 1995). Hacia 1997 el paramilitarismo se articula en una estructura nacional constituyendo las Autodefensas Unidas de Colombia (AUC). Los bloques Calima y Farallones de las AUC desembarcan en el Cauca donde combaten a los frentes 30 y 6 y a la columna móvil Jacobo Arenas del Comando Conjunto de Occidente de las FARC (Medina, 2011). En el marco de esta disputa
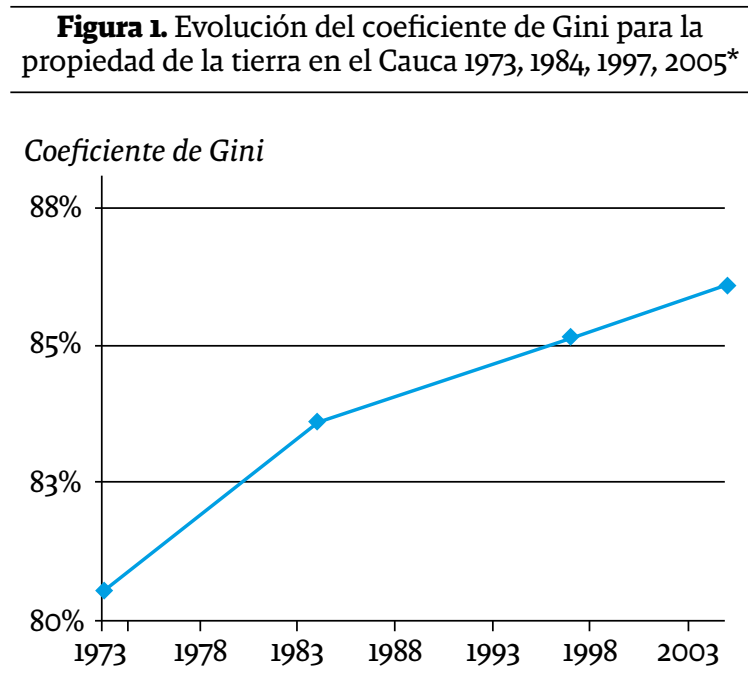

* Informes posteriores dan cuenta de la continuidad del incremento del coeficiente de Gini en todas sus dimensiones al menos hasta el 2009 (IGAC, 2012).

Fuente: Gamarra (2007). 
territorial se producen varias masacres, como la de la hacienda El Nilo en el municipio de Caloto perpetrada por agentes de la Policía Nacional y grupos parainstitucionales (CIDH, 2000) y la masacre del Río Naya en la que el Bloque Farallones de las AUC asesina a cuarenta campesinos y produce el desplazamiento forzado de más de mil personas. La intensificación del conflicto armado desde 1999, producto en buena medida del desembarco paramilitar en el departamento, queda de manifiesto en la figura 2.

La acción paramilitar ganó preponderancia desde el 2004 al ser apoyada por el propio gobernador departamental, Juan José Chaux Mosquera, que se propuso la "regeneración" del Cauca tras la salida del gobernador indígena Floro Tunubalá. En la figura 3 puede observarse una evolución conjunta -complementaria- de las tendencias de la violencia paramilitar y estatal ${ }^{8}$. Este modus operandi da cuenta y razón de la existencia de una alianza narco-paramilitar-terrateniente en el departamento (Sánchez et al., 2011, p. 89) que busca revertir el proceso de recuperaciones y contestar la ofensiva que las FARC despliegan desde $1990^{9}$.

La política de seguridad democrática instaurada por el presidente Álvaro Uribe Vélez consolida la

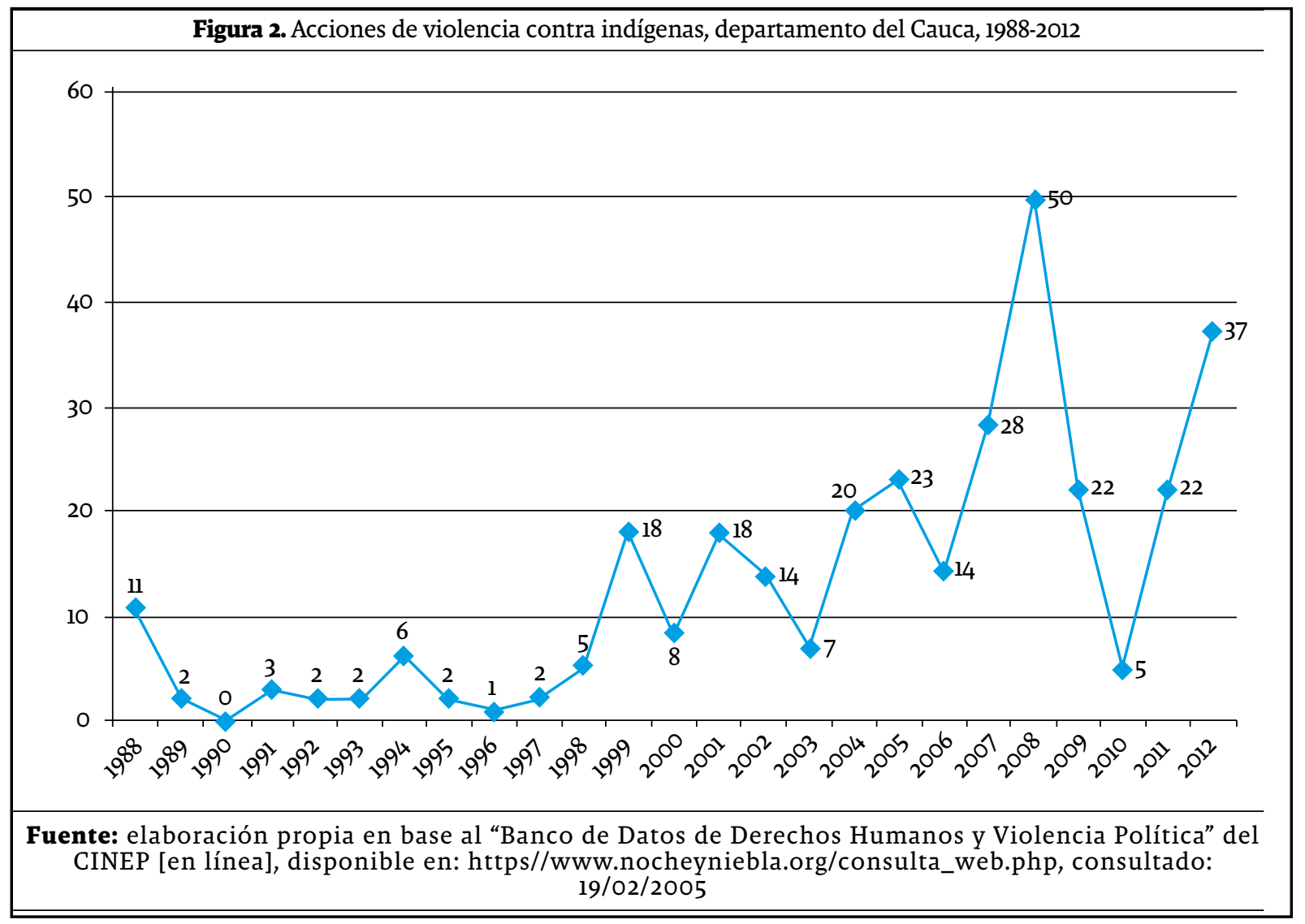

8. La tendencia congruente de la violencia estatal y parainstitucional abona la hipótesis de Medina Gallego y Téllez (fuente) (ver nota al pie $\mathrm{N}^{\circ}$ 3) que postula esta segunda forma de violencia como un elemento socio-histórico de larga duración en la construcción de la estatalidad colombiana.
9. A este escenario hay que sumar el nuevo papel que el departamento del Cauca desmpeña en la economía narcotraficante: a su carácter de articulador entre eslabones de la cadena productiva suma ahora su condición de zona de cultivo de coca (Sánchez et. al., 2011, p. 97). 
Figura 3. Acciones de violencia contra indígenas por actor responsable, departamento del Cauca, 1999-2012

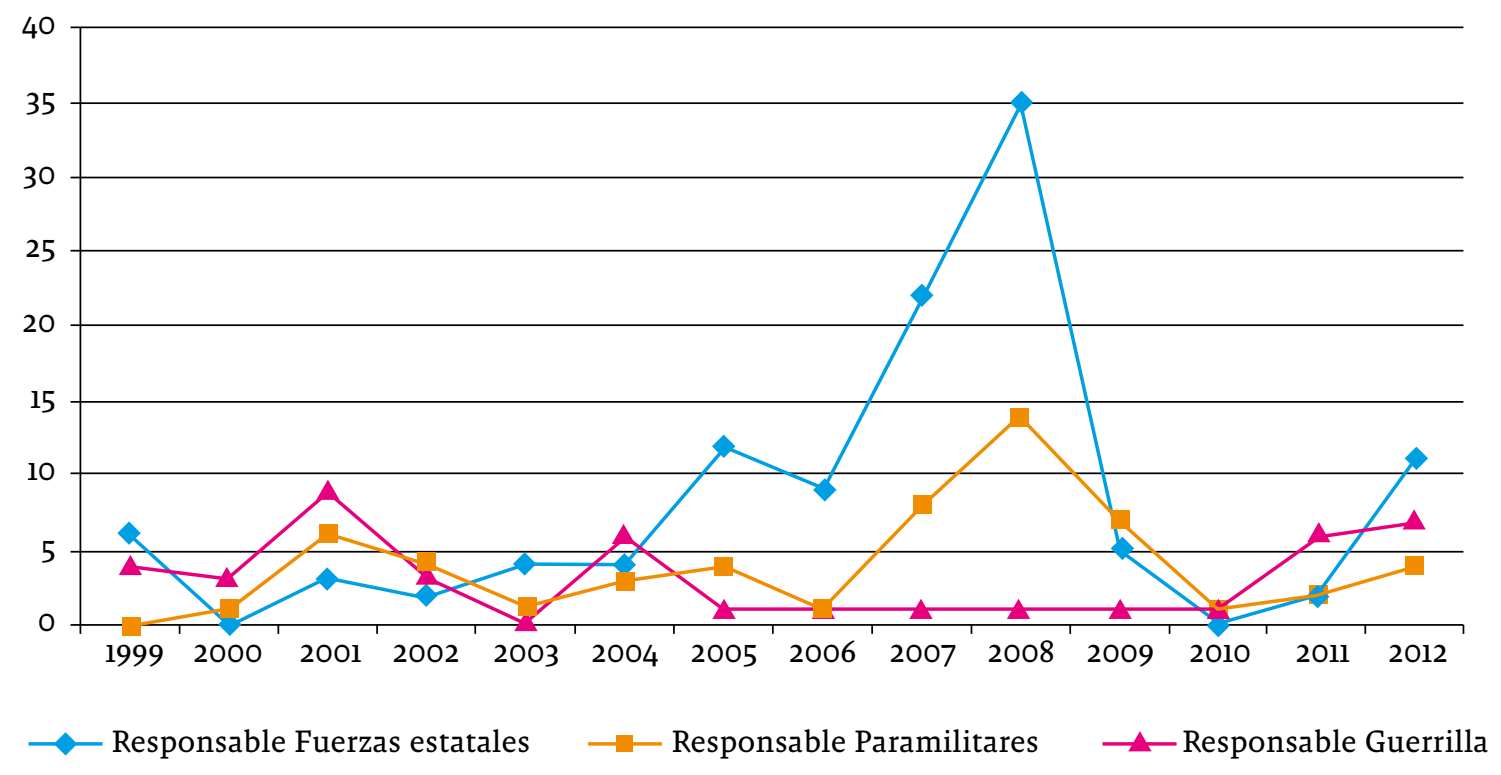

Fuente: elaboración propia en base al "Banco de Datos de Derechos Humanos y Violencia Política" del CINEP [en línea], disponible en: https//www.nocheyniebla.org/consulta_web.php, consultado: $19 / 20 / 2005$

nueva lógica del conflicto armado. Para enfrentar a las guerrillas el nuevo modelo operativo adoptado por las fuerzas estatales combina formas convencionales de la confrontación militar con formas irregulares o híbridas. Esta orientación de seguridad busca operar a través de socios y aliados, con lo cual la articulación entre la violencia estatal y la violencia parainstitucional que registramos arriba se refuerza (Medina, 2011, p. 36). La acción guerrillera también se modifica en este período. La guerrilla se vincula al narcotráfico y se interesa más por el control territorial y por los recursos que por la aceptación de la población (Moreno, 2008). Como resultado de esta guerra cada vez más irregular las poblaciones aparecen directamente involucradas. El escenario del conflicto armado se traslada a los territorios de las comunidades campesino-indígenas, amenazando sus modos de vida.

La opción por la resistencia armada por parte de las poblaciones campesino-indígenas resultará poco eficiente para defender la territorialidad comunitaria frente a la nueva dinámica del conflicto armado. A su vez, la redefinición del Estado nación colombiano, a partir de la reforma constitucional de 1991, operó como un marco de oportunidades favorable para el despliegue de una estrategia de resistencia civil al establecer un reconocimiento diferencial de las adscripciones étnicas, instaurando derechos y recursos específicos. La constitución colombiana de 1991 afirma el carácter multicultural de la sociedad e incorpora nuevos derechos, tales como el derecho consuetudinario, el derecho a la propiedad colectiva, el derecho a la educación bilingüe, el carácter oficial de las lenguas indígenas en sus territorios y las autonomías territoriales en el ámbito municipal. En el nuevo escenario de gestión estatal de la diversidad los pueblos indígenas aparecen dotados de recursos financieros mediante la transferencia directa de recursos a los cabildos. Los cabildos indígenas en 1994 reciben \$4858 millones mientras que en 2012 esa suma asciende a \$133.305 millones. Desde 1994 hasta el 2010 el Cauca es el departamento que recibe mayores ingresos, superando porcentualmente su proporción poblacional: según los datos censales del 2005 en el Cauca habita 17,85\% de la población indígena 
nacional, pero sus resguardos reciben en ese año $24,54 \%$ de los ingresos territoriales (tabla 1 ).

Además, las identidades de base étnica ganan espacios de participación político-electoral gracias al proceso de descentralización y participación ciudadana y gracias al establecimiento de las circunscripciones indígenas especiales, que aseguran el acceso a curules en el Congreso (Laurent, 2010), como puede constatarse en la tabla 2.
La re-imaginarización de la nación colombiana favorece las identidades étnicamente definidas, desalentando los procesos de articulación entre las comunidades indígenas y las guerrillas. En el nuevo contexto la negociación y el compromiso con los poderes políticos parecen ofrecerles a las comunidades mayores promesas que la confrontación armada. Los cabildos se verán atravesados por la lógica burocrática de la administración estatal. Representantes indígenas lograrán ser elegidos en

\begin{tabular}{|c|c|c|c|c|c|c|c|c|c|c|c|}
\hline Departamento & 2002 & 2003 & 2004 & 2005 & 2006 & 2007 & 2008 & 2009 & 2010 & 2011 & 2012 \\
\hline Antioquia & 1,81 & 1,84 & 1,76 & 1,76 & 1,75 & 1,76 & 1,74 & 1,76 & 1,78 & 1,78 & 1,81 \\
\hline Boyacá & 0,61 & 0,40 & 0,38 & 0,39 & 0,37 & 0,37 & 0,39 & 0,43 & 0,43 & 0,44 & 0,44 \\
\hline Caldas & 6,47 & 6,37 & 7,09 & 6,97 & 6,90 & 6,74 & 6,16 & 5,53 & 5,28 & 5,02 & 4,55 \\
\hline Caqueta & 0,72 & 0,73 & 0,72 & 0,72 & 0,75 & 0,74 & 0,70 & 0,48 & 0,49 & 0,50 & 0,50 \\
\hline Cauca & 25,31 & 24,55 & 24,50 & 24,54 & 24,51 & 24,39 & 23,27 & 22,45 & 22,21 & 21,92 & 21,81 \\
\hline Cesar & 2,43 & 2,43 & 3,10 & 3,06 & 3,10 & 3,15 & 3,85 & 3,97 & 4,00 & 3,99 & 4,03 \\
\hline Córdoba & 3,39 & 3,30 & 3,11 & 3,26 & 3,17 & 3,28 & 4,11 & 4,68 & 4,74 & 4,81 & 2,64 \\
\hline Chocó & 4,98 & 5,02 & 4,94 & 4,95 & 4,94 & 4,93 & 4,77 & 4,95 & 5,02 & 5,06 & 5,10 \\
\hline Huila & 0,14 & 0,24 & 0,68 & 0,58 & 0,65 & 0,67 & 0,65 & 0,63 & 0,63 & 0,63 & 0,63 \\
\hline Guajira & 20,17 & 20,28 & 19,15 & 19,30 & 19,29 & 19,46 & 21,01 & 22,06 & 22,34 & 22,39 & 22,59 \\
\hline Magdalena & 0,96 & 0,94 & 0,88 & 0,88 & 0,87 & 0,86 & 0,82 & 0,78 & 0,77 & 0,78 & 0,81 \\
\hline Meta & 1,12 & 1,12 & 1,08 & 1,09 & 1,09 & 1,08 & 0,99 & 1,00 & 1,02 & 1,02 & 1,03 \\
\hline Nariño & 11,03 & 11,43 & 11,35 & 11,10 & 11,01 & 11,03 & 11,14 & 11,47 & 11,53 & 11,78 & 11,85 \\
\hline N. de Santander & 0,47 & 0,57 & 0,54 & 0,53 & 0,53 & 0,53 & 0,48 & 0,46 & 0,45 & 0,45 & 0,45 \\
\hline Quindío & 0,00 & 0,00 & 0,00 & 0,00 & 0,00 & 0,00 & 0,00 & 0,00 & 0,00 & 0,02 & 0,02 \\
\hline Risaralda & 1,18 & 1,36 & 1,28 & 1,26 & 1,25 & 1,22 & 1,12 & 1,05 & 1,03 & 1,01 & 0,98 \\
\hline Santander & 0,00 & 0,11 & 0,10 & 0,09 & 0,10 & 0,10 & 0,10 & 0,10 & 0,10 & 0,09 & 0,09 \\
\hline Sucre & 1,73 & 1,74 & 1,64 & 1,63 & 1,63 & 1,63 & 1,70 & 1,67 & 1,65 & 1,65 & 1,66 \\
\hline Tolima & 2,38 & 2,39 & 2,35 & 2,35 & 2,37 & 2,40 & 2,22 & 2,16 & 2,18 & 2,29 & 2,35 \\
\hline Valle del Cauca & 0,92 & 0,97 & 0,90 & 0,91 & 0,91 & 0,91 & 0,90 & 0,95 & 0,95 & 0,93 & 0,93 \\
\hline Arauca & 0,41 & 0,41 & 0,39 & 0,40 & 0,40 & 0,40 & 0,38 & 0,39 & 0,41 & 0,41 & 0,42 \\
\hline Casanare & 0,79 & 0,80 & 0,76 & 0,76 & 0,76 & 0,75 & 0,69 & 0,63 & 0,63 & 0,62 & 0,62 \\
\hline Putumayo & 1,95 & 2,00 & 2,18 & 2,25 & 2,41 & 2,47 & 2,33 & 2,36 & 2,44 & 2,49 & 2,56 \\
\hline Amazonas & 2,96 & 3,00 & 2,99 & 2,99 & 3,00 & 2,96 & 2,76 & 2,57 & 2,58 & 2,66 & 4,91 \\
\hline Guainia & 2,11 & 1,98 & 1,88 & 1,89 & 1,90 & 1,87 & 1,77 & 1,72 & 1,69 & 1,63 & 1,58 \\
\hline Guaviare & 0,65 & 0,66 & 0,65 & 0,65 & 0,69 & 0,74 & 0,80 & 0,92 & 0,95 & 0,95 & 0,97 \\
\hline Vaupés & 2,58 & 2,57 & 2,47 & 2,48 & 2,44 & 2,39 & 2,21 & 2,00 & 1,90 & 1,87 & 1,84 \\
\hline Vichada & 2,73 & 2,79 & 3,17 & 3,17 & 3,21 & 3,17 & 2,93 & 2,81 & 2,78 & 2,79 & 2,83 \\
\hline Total & 100,00 & 100,00 & 100,00 & 100,00 & 100,00 & 100,00 & 100,00 & 100,00 & 100,00 & 100,00 & 100,00 \\
\hline
\end{tabular}

Fuente: elaboración propia con base en información del Departamento Nacional de Planeación, Dirección de Desarrollo Territorial. 
varias alcaldías de los municipios de mayoría indígena y por primera vez un indígena guambiano accederá al gobierno del Cauca. Este avance político electoral será castigado por la violencia armada de los grupos parainstitucionales y también de las guerrillas, especialmente las FARC, que asumirán al movimiento indígena como parte del establishment y lo considerarán objetivo militar.

La nueva lógica del conflicto armado y la redefinición de las políticas de gestión estatal de la diversidad consolidarán la opción por la resistencia civil por parte de las comunidades indígenas organizadas en el CRIC. La resistencia civil a la violencia política será practicada a partir de un conjunto de repertorios de acción que se estructuran en dos sentidos. Por una parte se producen formas específicas de resistencia civil contra la guerra y los efectos del conflicto armado, entre las cuales se destacan las acciones de neutralización de los actores armados llevadas a cabo por la guardia indígena, las asambleas permanentes en las situaciones de fuego cruzado, las audiencias públicas para juzgar los crímenes de guerra, y las comisiones masivas de búsqueda y rescate de personas secuestradas por los actores armados (Hernández, 2003; Hernández, 2006; Moreno, 2008). Por la otra, se recuperan formas de lucha típicas de los movimientos sociales que se resignifican al practicarse como mingas -colectivamente-, se cuentan en este aspecto las movilizaciones intersectoriales hacia Popayán y Cali, entre otras.

La opción por la resistencia civil tomó una dimensión pública nacional con el establecimiento del "Territorio de Convivencia, Diálogo y Negociación" en La María, Piendamó, imitando la zona de distención que el gobierno nacional y las FARC habían abierto en el Caguán. Este espacio será ofrecido por el CRIC para establecer negociaciones de paz con el Estado y los actores armados. En sus declaraciones públicas y en sus prácticas de resistencia las comunidades indígenas del Cauca buscarán afirmar su autonomía territorial rechazando a todos los actores armados, incluidas las fuerzas del Estado.

En el 2000 el cabildo de Jambaló procede a la destrucción de campamentos y laboratorios de narcotraficantes. Iniciando una práctica que sería recurrente en los años venideros, el CRIC convoca ese año a la "Primera Audiencia Pública por la Vida y la Esperanza" para denunciar los ataques y amenazas de los actores armados sobre miembros de las comunidades. Al mismo tiempo se establece oficialmente la Guardia Indígena en el Congreso Extraordinario de Caloto. La Guardia Indígena, una institución con antecedentes en las luchas anticoloniales del pueblo nasa, se conforma ahora como un cuerpo de defensa civil, integrado mayormente por jóvenes de las comunidades que tienen como misión defender los planes de vida y proteger el territorio frente a "todos los factores de violencia" (ONIC, 2002, p. 58). Además de la Guardia Indígena se dará inicio a la estrategia de asambleas permanentes, espacios seguros en el territorio a los que la comunidad se dirige para debatir las acciones a seguir cuando se producen los enfrentamientos armados. Con las asambleas permanentes, que para mediados de la década del 2000 son más de 60 en el norte del Cauca, se consigue evitar el desplazamiento individual de la población y se sostiene la presencia en el territorio.

A su vez el avance electoral indígena consolida la multiplicación de estrategias colectivas de afirmación territorial mediante los llamados "Planes de Vida"1o ${ }^{\prime \prime}$. Definidos en asamblea por la totalidad de los miembros de las comunidades, los Planes de Vida establecen prioridades organizativas y líneas de acción territorial que incluyen el desarrollo

10 La primera de estas iniciativas se formalizó en 1980 con el llamado "Proyecto Nasa" en Toribío, cuyos programas de trabajo comprendieron producción, familia, vivienda, salud, educación, evangelización, trabajo comunitario, tiendas y empresas comunitarias (Rudqvist y Anrup, 2013). Siguiendo el ejemplo del Proyecto Nasa se crea en 1990 el "Proyecto Unidad Páez" de Miranda y el "Proyecto Integral" de Caloto, en 1991 el "Proyecto Cxa Cxa Wala" de Corinto y el "Proyecto Yu'lucx" de Santander y Buenos Aires, el "Plan de Vida" de Silvia y en el 2001 se reestructura el "Plan Global" de Jambaló promulgándose el "Plan de Defensa de la Vida, Respeto y Control del Territorio". La creación en 1994 de la Asociación de Cabildos del Norte del Cauca, una organización de segundo grado que articula los 12 cabildos de la región, resulta fundamental para el impulso de estas iniciativas. También en la subregión de Tierradentro se adelantan trabajos para la discusión de los planes de vida comunitarios a instancias de sus dos asociaciones de cabildos, Juan Tama y Nasa Çxhâçxha. 
comunitario pero también la educación intercultural bilingüe, la justicia indígena, la acción frente a los actores armados, la logística en contextos de desastres naturales y la recuperación de la lengua y la cultura. De este modo las comunidades pretenden defender su territorialidad frente a los actores externos, sean estos armados o no y afirmarse en sus modos de vida. Esta posición quedará expresada en la resolución "por la Autonomía de los pueblos indígenas frente a los conflictos que atentan contra nuestro proyecto de vida" elaborada por el Cabildo de Jambaló.

A estas formas de resistencia civil se le suman las movilizaciones intersectoriales de gran masividad que reciben el nombre de "Mingas de Resistencia". En la "Gran Minga por la Vida y contra la Violencia", convocada como respuesta a la masacre del Río Naya, son 35.000 los indígenas y campesinos que marchan desde Santander de Quilchao hasta Cali (Hernández, 2003). Para el año 2004 suman 65.000 los indígenas de diversas organizaciones que marchan a Cali en protesta contra la Política de Seguridad Democrática (Sánchez et al., 2011, p. 96). Dos años después más de 300.000 personas entre pueblos indígenas y organizaciones sociales se reúnen en el resguardo de La María en ocasión de la Cumbre Nacional Itinerante de Organizaciones Sociales y reclaman la convocatoria a una consulta nacional para dirimir la firma al Tratado de Libre Comercio con Estados Unidos (TLC). En el 2008 se llevó a cabo la "Minga de Resistencia Social y Comunitaria" que incluyó cortes de vías y un llamado explícito al presidente de la Nación, Álvaro Uribe Vélez, para que se acerque a dialogar con las comunidades. En esta ocasión la represión de las fuerzas estatales fue especialmente intensa y se articuló con la acción de sectores parainstitucionales en una estrategia de "tierra arrasada", tal como queda de manifiesto en la figura 2. Frente a la conmoción pública por lo sucedido el presidente se vio obligado a acudir a La María y escuchar los reclamos de las organizaciones del Cauca.

En los últimos años la concentración de la propiedad rural se profundizó a partir de la aprobación del TLC con los Estados Unidos bajo el mandato de Juan Manuel Santos y la promulgación de una serie de leyes que marcan una clara orientación en la política económica rural hacia la explotación de materias primas y la industrialización a gran escala de procesos extractivos (Planeta Paz, 2012; Fajardo, 2015). Tal orientación económica redunda en el Cauca en un proceso de concentración de las tierras de mejor calidad mediante la adquisición de grandes predios por parte de unos pocos propietarios (IGAC, 2012). Presentado este panorama no es de extrañar que en este período se profundicen una serie de conflictos contra el modelo extractivo (Giarraca y Teubal, 2013), fundamentalmente en los terrenos de producción cañera". Este modelo se vio favorecido por las facilidades impositivas, arancelarias y crediticias de la Ley Páez de 1995 y por los estímulos otorgados a la producción de biocombustibles (Sánchez et al., 2011) y se articuló rápidamente con los sectores parainstitucionales. En septiembre del 2005 comienza en el norte del Cauca un proceso de recuperaciones de tierras y resistencia al monocultivo industrial de caña de azúcar que la Asociación de Cabildos del Norte del Cauca (ACIN) denomina "Liberación de la Madre Tierra" y que aún continúa ${ }^{12}$.

La resistencia a la violencia política y la recreación de la territorialidad comunitaria llega a un punto de especial trascendencia mediática con el conflicto por la desmilitarización de Toribío, un municipio muy afectado por la lucha entre los actores del conflicto armado. En julio del 2012, cuatro meses antes de que el presidente Juan Manuel Santos comunicara al país el inicio de los últimos diálogos de paz, la ACIN procedió a incautar armamento guerrillero, desmantelar trincheras policiales, ocupar vías de acceso estratégico y tomar bases de las Fuerzas Armadas. Cumplido el ultimátum que la organización había dado a los militares ubicados en el Cerro Berlín, los guardias indígenas procedieron a cargar en brazos a los soldados para desalojarlos. Las imágenes del sargento llorando sobre

11 Desde los años de 1980 la resistencia indígena no armada luchó contra agentes externos que desarrollaban megaproyectos, como en el caso del embalse Salvajina o en el de la explotación de bosques de la multinacional Cartón de Colombia. Sin embargo este tipo de conflictos va a ganar preponderancia desde los años 2000 (Sánchez et al., 2011).

12 La última toma de La Emperatriz ocurrió hacia fines del 2014 y se continúa hasta la actualidad resistiendo la represión de las fuerzas estatales de seguridad. 
los brazos de los guardias indígenas recorrieron el mundo y obligó vez más al presidente a acudir a La María.

\section{Conclusiones}

La lucha de las comunidades indígenas organizadas en el CRIC expresa un conflicto entre distintas territorialidades en pugna. La tierra aparece para los actores armados como espacio estratégico de control político, económico y militar; para los sectores narcotraficantes y las empresas agroindustriales la tierra constituye una mercancía o un recurso a explotar; y para los indígenas ella está vinculada a una forma de vida, a una autoridad propia y a la reproducción espiritual y material de sus comunidades. Estas territorialidades, que constituyen diversos proyectos de orden social, han apelado a distintas formas de violencia política.

La resistencia a la violencia política del CRIC constituye un proceso de recreación de la territorialidad comunitaria que se ha gestado en una temporalidad de largo aliento. En el período de mediano alcance que recortamos para este trabajo identificamos dos estrategias principales en las que se desplegó la resistencia indígena. Entre 1971 y 1991 las comunidades indígenas resistieron apelando a la violencia armada -primero a partir del establecimiento de alianzas con sectores insurgentes y luego mediante la construcción de una guerrilla indígena-, mientras que desde 1992 se consolidó la opción por la resistencia civil. A la hora de explicar estas transformaciones consideramos los efectos de tres variables: las políticas estatales de distribución y uso de la tierra, el desarrollo histórico del conflicto armado y la imaginarización de la nación con sus modos estatales de gestión de la diversidad. La resistencia armada a la violencia política por parte de las comunidades indígenas (1971-1991) se explica por la confluencia de tres factores: el bloqueo de la vía legal para la recuperación de tierras, la persistencia de un imaginario nacional que asimila al indígena con el pasado y postula su campesinización, y la adopción de una lógica partisana con subordinación al mando político por parte de las organizaciones guerrilleras. La preponderancia de la opción por la resistencia civil a la violencia política (1992-2012) se explica, primero, porque frente al recrudecimiento del conflicto armado y a la redefinición de sus lógicas de funcionamiento las guerrillas y los ejércitos paramilitares aparecerán como una amenaza a la territorialidad comunitaria; y segundo, porque la redefinición del Estado nación colombiano, a partir de la reforma constitucional, operó como un marco de oportunidades favorable para el despliegue de dicha estrategia de resistencia al establecer un reconocimiento diferencial de las adscripciones étnicas, instaurando derechos y recursos específicos.

\section{Referencias}

Ansaldi, W. y Alberto, M. (2014). Muchos hablan de ella, pocos piensan en ella. Una agenda posible para explicar la apelación a la violencia política en América latina. En W. Ansaldi y V. Giordano (Coords.), América Latina. Tiempos de Violencias (pp. 27-46). Buenos Aires, Argentina: Ariel.

Castillo, L. C. (2006). El Estado-Nación pluriétnico y multicultural colombiano: la lucha por el territorio en la reimaginación de la nación y la reinvención de la identidad étnica de negros e indígenas (tesis de doctorado). Universidad Complutense de Madrid, Madrid, España.

Centro de Investigación y Educación Popular -CINEP- [en línea]. Banco de Datos de Derechos Humanos y Violencia Política, recuperado de: https//www.nocheyniebla.org/consulta_web.php, consultado: $19 / 02 / 2005$

CIDH -Comisión Interamericana de Derechos Humanos-. (2000). Informe No. 36/00. Recuperado de https:// www.cidh.oas.org/annualrep/99span/De\%20Fondo/Colombiallol.htm

CNMH -Comisión Nacional de Memoria Histórica-. (2013). La política de reforma agraria y tierras en Colombia. Esbozo de una memoria institucional. Bogotá, Colombia: Imprenta Nacional. 
Decreto 1923/78 - Ministerio de Justicia y del Derecho. Decreto legislativo 1923 de 1978 "Por el cual se dictan normas para la protección de la vida, honra y bienes de las personas y se garantiza la seguridad de los asociados", recuperado de: https://www.minjusticia.gov.co/portals/o/MJD/docs/decreto_1923_1978.htm

Espinosa, M. L. (2007). Memoria cultural y el continuo del genocidio: lo indígena en Colombia. Antípoda, (5), 53-73.

Fajardo, D. (2015). Colombia: agricultura y capitalismo. En G. Almeyra, M. P. Concheiro, J. Máricio y C. W. Porto (Coords.), Capitalismo: tierra y poder en América Latina (1982-2012). Vol. II (pp. 65-122). México D. F., México: CLACSO.

Galtung, J. (1998). Tras la violencia, 3R: reconstrucción, reconciliación, resolución: afrontando los efectos visibles e invisibles de la guerra y la violencia. Bilbao, España.

Gamarra-Vergara, J. (2007). La economía del Departamento del Cauca: concentración de tierras y pobreza Cartagena, Colombia Banco de la República.

Giarraca, N. y Teubal, M. (Coords.). (2013). Actividades extractivas en expansión. ¿Reprimarización en la economía argentina? Buenos Aires, Argentina: Antropofagia.

González, N. C. (2006). Resistencia Indígena. Alternativa en medio del conflicto colombiano. Cali, Colombia: Editorial de la Universidad Javeriana.

González, F. E., Bolívar, I. J. y Vázquez, T. (2002). Violencia política en Colombia. De la nación fragmentada a la construcción del Estado. Bogotá, Colombia: CINEP.

Hernandez, E. (2004). Resistencia civil artesana de paz. Experiencias indígenas, Afrodescendientes y campesinas. Bogotá, Colombia: Editorial de la Universidad Javeriana.

Hernández, E. (2006). La resistencia civil de los indígenas del Cauca. Papel Político, 11(1), 177-220.

Hernández, J. (2002). La resistencia civil en caliente: una contribución a la pacificación del conflicto en Colombia. Sociedad y Economía, (2), 21-38.

Hernández, J. (2003). Formas de acción colectiva contra la guerra en el movimiento indígena del suroccidente colombiano. Sociedad y Economía, (5), 109-124.

Ibeas, J. (1995). Génesis y desarrollo de un movimiento armado indígena en Colombia. América Latina Hoy, $10,37-48$.

IGAC -Instituto Geográfico Agustín Codazzi-. (2012). Atlas de la distribución de la propiedad rural en Colombia. Bogotá, Colombia: Imprenta Nacional.

Laurent, V. (2010). Con bastones de mando o en el tarjetón. Movilizaciones políticas indígenas en Colombia. Colombia Internacional, (71), 35-71.

Lemaitre, J. (2013). ¡Viva nuestro derecho! Quintín Lame y el legalismo popular. En J. Lemaitre (Comp.), La Quintiada (1912-1925): la rebelión indígena liderada por Manuel Quintín Lame en el Cauca: recopilación de fuentes primarias (pp. 221-260). Bogotá, Colombia: Universidad de los Andes.

Medina, C. (Ed.). (2011). FARC-EP flujos y reflujos: la guerra en las regiones. Bogotá, Colombia: Universidad Nacional de Colombia. 
Moreno, R. (2008). Las organizaciones indígenas y campesinas frente al conflicto armado en el norte del Cauca. Sociedad y Economía, (15), 145-167.

ONIC -Organización Nacional Indígena de Colombia-. (2002). Los indígenas y la paz. Pronunciamientos, resoluciones, declaraciones y otros documentos de los pueblos y organizaciones indígenas sobre la violencia armada en sus territorios, la búsqueda de la paz, la autonomía y la resistencia. Bogotá, Colombia: Turdakke.

Peñaranda, D. R. (Coord.). (2012). Nuestra vida ha sido nuestra lucha. Resistencia y memoria en el Cauca indígena. Bogotá, Colombia: Centro Nacional de Memoria Histórica.

Peñaranda, D. R. (2015). Guerra propia, guerra ajena. Conflictos armados y reconstrucción identitaria en los Andes colombianos. El Movimiento Armado Quintín Lame. Bogotá, Colombia: CNMH.

Peñaranda, D. R., Guerrero, J. y Zuluaga, J. (1999). De las armas a la política. Bogotá, Colombia: IEPRI.

Pineda, R. (1997). La constitución de 1991 y la perspectiva del multiculturalismo en Colombia. Alteridades, $7(14), 107-129$.

Planeta Paz. (2012). La cuestión agraria en Colombia: tierra desarrollo y paz. Bogotá, Colombia: Planeta Paz.

Platt, T. (1999). La persistencia de los ayllus en el norte de Potosí. De la invasión europea a la república de Bolivia. La Paz, Bolivia: Fundación Diálogo.

Presidencia de la República. (2008). Informe ejecutivo, Tierras para las comunidades indígenas. Recuperado de www.historico.presidencia.gov.co/sp/2008/octubre/31/especial_07312008.pdf

PEBI -Programa de Educación Bilingüe Intercultural-. (2004). ¿Qué pasaría si la escuela...? Treinta años de construcción educativa. Popayán, Colombia: Consejo Regional Indígena del Cauca.

Pumarada, Y. C. (2013). Othering Modernization: the Nasa Margins of Colombia (1890-1930s) (tesis de doctorado). Universidad de Wisconsin-Madison, Madison, Wisconsin, Estados Unidos.

Rappaport, J. (1990). The Politics of Memory. Native Historical Interpretation in the Colombian Andes. Cambridge, UK: Cambridge University Press.

Rappaport, J. (2004). Manuel Quintín Lame hoy. En M. Quintín Lame, Los pensamientos del indio que se educó dentro de las selvas colombianas (pp. 51-101). Cali y Popayán, Colombia: Editoriales Universidad del Valle/Universidad del Cauca.

Rodríguez, P. (2016). El Leviatán en la sombra. Violencia parainstitucional en Colombia (1945-2010). Desafíos para la teoría. En E. A. Busto y R. Rodríguez (Comps.), Actas de las I Jornadas Nacionales e Internacionales en Estudios Latinoamericanos y del Caribe. Mar del Plata, Argentina: Universidad Nacional de Mar del Plata.

Rudqvist, A. y Anrup, R. (2013). Resistencia comunitaria en Colombia. Los cabildos caucanos y su guardia indígena. Papel Político, 18(2), 515-548.

Sánchez, L. C., Vargas, A. R. y Vázquez, T. (2011). Las diversas trayectorias de la guerra. Un análisis subregional. En T. Vásquez, A. Vargas, y J. A. Restrepo (Eds.), Una vieja guerra en un nuevo contexto. Conflicto y territorio en el sur de Colombia (pp. 81-83). Bogotá, Colombia: Editorial Javeriana.

Sandoval, E. A. (2008). La guardia indígena nasa y el arte de la resistencia pacífica. Bogotá, Colombia: Hemera.

Villa, W. y Houghton, J. (2005). Violencia política contra los pueblos indígenas en Colombia 1974-2004. Bogotá, Colombia: CECOIN-OIA. 